\title{
Exploring Drug Overdose Mortality Data in Harris County,
}

\section{Texas}

\section{Eric V. Bakota, Deborah Bujnowski, Larissa Singletary, Sherri Onyiego, Nadia Hakim, Dana Beckham}

Health Department, Harris County Public Health, Houston, Texas, United States

\section{Objective}

In this session, we will explore the results of a descriptive analysis of all drug overdose mortality data collected by the Harris County Medical Examiner's Office and how that data can be used to inform public health action.

\section{Introduction}

Drug overdose mortality is a growing problem in the United States. In 2017 alone over 72,000 deaths were attributed to drug overdose, most of which were caused by fentanyl and fentanyl analogs (synthetic opioids) [1]. While nearly every community has seen an increase in drug overdose, there is considerable variation in the degree of increase in specific communities. The Harris County community, which includes the City of Houston, has not seen the massive spikes observed in some communities, such as West Virginia, Kentucky, and Ohio. However, the situation in Harris County is complicated in mortality and drug use.

From 2010 - 2016 Harris County has seen a fairly stable overdose-related mortality count, ranging from 450 - 618 deaths per year. Of concern, the last two years, 2015-2016, suggest a sharp increase has occurred. Another complexity is that Harris County drug related deaths seem to be largely from polysubstance abuse.

Deaths attributed to cocaine, methamphetamine, and benzodiazipine all have risen in the past few years. Deaths associated with methamphetamine have risen from approximately 20 per year in 2010 - 2012 to 119 in 2016 . This 6-fold increase is alarming and suggests a large-scale public health response is needed.

\section{Methods}

Data were collected by the Harris County Institute of Forensic Sciences (IFS), which is part of the Harris County Medical Examiner's Office. IFS is the agency responsible for collecting and analyzing human tissue of the deceased for toxicological information about the manner and cause of death. IFS is able to test for the presence of multiple substances, including opioids, benzodiazepines, methamphetamines, cocaine, ethanol, and many others.

These data were cleaned and labeled for the presence of opioids, cocaine, benzodiazepine, Z-drug (novel drug), amphetamines, ethanol, and carisoprodol. Explorative descriptive analyses were then completed in R (version 3.4) to identify trends. An RShiny app was created to further explore the data by allowing for rapid filtering and/or subsetting based on various demographic characteristics (e.g., age, sex, race).

\section{Results}

We found that Harris County is experiencing a modest upward trend of drug related overdoses, with 529 observed in 2010 and 618 in 2016. We also found that the increase was not uniform across all classified drugs: amphetamines, cocaine, and ethanol all saw increases. Deaths involving amphetamine increased substantially from 21 in 2010 to 119 in 2016 (Figure 1). Deaths involving cocaine saw the next sharpest increase with 144 in 2010 and 237 in 2016. Deaths associated with opioids remained fairly constant, with 291 deaths in 2010 and 271 deaths in 2016.

Differences in mortality across race and sex groups were also observed. The proportion of amphetamine deaths among whites jumped sharply, while the proportion of opioid and benzodiazepine deaths among whites decreased in recent years. The proportion of amphetamine and cocaine deaths among men rose more sharply than with women in the past three years, whereas for opioids, the proportion of women dying has dropped. AttributionNoncommercial 4.0 Unported License (http://creativecommons.org/licenses/by-nc/3.0/), permitting all non-commercial use, distribution, and reproduction in any medium, provided the original work is properly cited. 


\section{Conclusions}

It is undeniable that the opioid epidemic is a true public health emergency for the nation. New surveillance tools are needed to better understand the impact and nature of this threat. Additionally, as we have found in Harris County, the threat may be polysubstance in nature.

Our report offers two important insights: 1) that mortality data is a useful and actionable surveillance resource in understanding the problem of substance abuse; and 2) public health needs to look at substance abuse from a holistic and comprehensive perspecti ve. Keeping the purview limited to opioids alone may create significant blind spots to the public health threat facing us.

\section{Acknowledgement}

We would like to acknowledge Emily Dean and Rhett Lacey for their significant work at HCPH to understand the threat of substance abuse, and Jason Wiersema and the team at IFS for help in obtaining and contexualizing the data.

\section{References}

1. National Institute of Health. (2018) Overdose Death Rates. Retreived from https://www.drugabuse.gov/relatedtopics/trends-statistics/overdose- death-rates

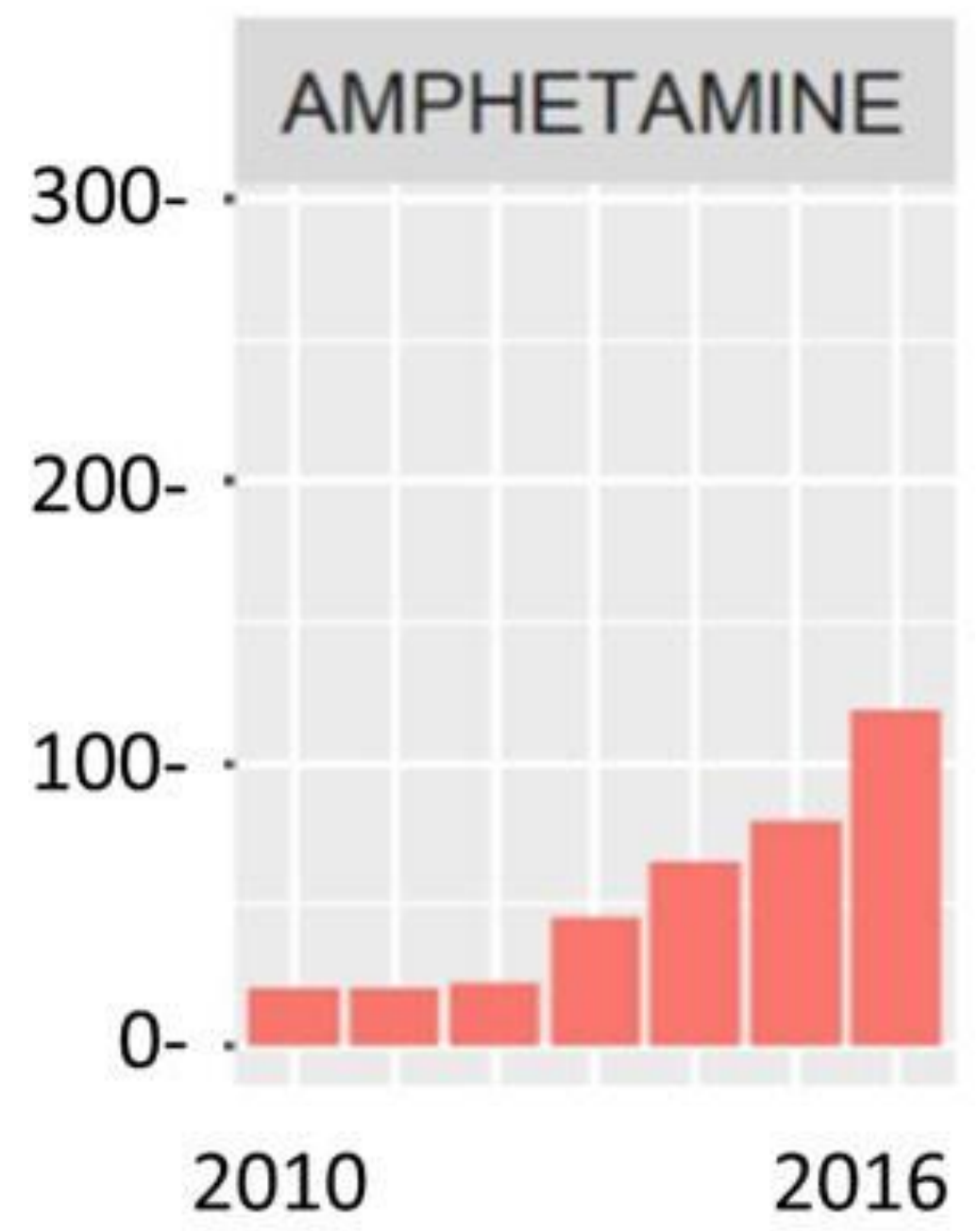

Figure 1. 